\title{
STAT3 cooperates with Twist to mediate epithelial-mesenchymal transition in human hepatocellular carcinoma cells
}

\author{
CHUANHAI ZHANG ${ }^{1,2^{*}}$, FENGLIN GUO $^{3 *}$, GELIANG XU ${ }^{1,2}$, JIE MA $^{1,2}$ and FENG SHAO ${ }^{1,2}$ \\ ${ }^{1}$ Department of Hepatic Surgery, Affiliated Provincial Hospital, Anhui Medical University; ${ }^{2}$ Centre for the Study of \\ Liver Cancer, Anhui Key Laboratory of Hepatopancreatobiliary Surgery; ${ }^{3}$ Department of Anesthesiology, \\ Affiliated Provincial Hospital, Anhui Medical University, Hefei, Anhui 230001, P.R. China
}

Received October 31, 2014; Accepted January 5, 2015

DOI: $10.3892 /$ or.2015.3783

\begin{abstract}
Epithelial-to-mesenchymal transition (EMT) is critical for the invasion and metastasis of hepatocellular carcinoma (HCC). However, to date, the association of signal transducer and activator of transcription 3 (STAT3) with EMT, and its mediated tumor invasion and metastasis in HCC, remain elusive. We investigated the relationship between STAT3 activation and EMT, and the underlying mechanisms involved in HCC progression. By stable transfection, we successfully overexpressed STAT3 in low metastatic SMMC7721 cells and silenced STAT3 expression in high metastatic MHCC97H cells. The EMT-associated molecular HCC cell changes were analyzed by real-time PCR, western blotting and immunocytochemical methods. The EMT-mediated HCC cell invasion and migration were evaluated by a Transwell cell invasion and cell migration assay, respectively. The interaction between STAT3 and Twist (a key EMT inducer) was evaluated by dual-luciferase reporter assay. In the present study, we found that STAT3 overexpression significantly reduced E-cadherin and $\beta$-cadherin, and it enhanced $\mathrm{N}$-cadherin and vimentin expression in the SMMC7721 cells. STAT3 knockdown significantly increased E-cadherin and $\beta$-cadherin, and it decreased $\mathrm{N}$-cadherin and vimentin expression in the MHCC97H cells. Meanwhile, a dual-luciferase reporter assay revealed that STAT3 may bind the Twist promoter, mediate its transcriptional activity, and then promote the EMT process in HCC cells. STAT3 activation-mediated EMT also evidently enhanced HCC cell invasion and migration. In summary, the present study demonstrated for the first time that STAT3
\end{abstract}

Correspondence to: Dr Chuanhai Zhang, Department of Hepatic Surgery, Affiliated Provincial Hospital, Anhui Medical University, 17 Lu-Jiang Road, Hefei, Anhui 230001, P.R. China

E-mail: zhangchuanhaisci@163.com

*Contributed equally

Key words: hepatocellular carcinoma, epithelial-mesenchymal transition, signal transducer and activator of transcription 3, Twist, invasion, migration may cooperate with Twist to mediate EMT and induce HCC invasion and metastasis. Activated STAT3, Twist, and EMT markers may serve as potential molecular targets in the prevention and/or treatment of HCC invasion and metastasis.

\section{Introduction}

Hepatocellular carcinoma (HCC) is one of the most aggressive malignant tumors, with limited treatment options. In order of mortality, it is the third most prevalent cancer worldwide and the second in China (1). To date, curative hepatectomy and transplantation are the most effective therapies for patients with HCC (2), yet the prognosis remains poor due to the high incidence of metastasis and recurrence, which is usually associated with a high propensity for vascular invasion and metastasis (3). Therefore, it is necessary to identify novel predictors to forecast invasive and metastatic HCC phenotypes.

Epithelial-to-mesenchymal transition (EMT) is an early event that occurs when cancer invades an epithelial origin. At the molecular level, EMT is characterized by epithelial cell marker loss, including the cell adhesion molecule E-cadherin, and also the acquiring of various mesenchymal markers $(4,5)$. Although the role EMT plays in tumor invasion and metastasis has been investigated, the underlying regulatory mechanisms involved remain unclear. In recent years, constitutive activation of signal transducer and activator of transcription 3 (STAT3) has been detected in a variety of human tumors, including HCC. Activated STAT3 (phosphorylated STAT3/p-STAT3, Tyr705) is often correlated with tumor invasion and metastasis (6-9). Huang et al reported that the STAT3 signaling pathway plays an important role in the pancreatic cancer EMT process by regulating Snail gene expression (10). Lo et al (11) and Cheng et al (12) found that activated STAT3 correlates positively with Twist expression in human breast cancer and it can transcriptionally induce Twist to mediate STAT3-related oncogenic functions. Moreover, a recent study showed that STAT3 mediates colorectal cancer EMT progression through the regulation of ZEB1 expression (13).

Since STAT3 activation and EMT play important roles in tumor invasion and metastasis, it is of great interest to explore whether activated STAT3 can mediate EMT to induce HCC progression. In our previous study, we demonstrated that STAT3 activation is associated with Twist and E-cadherin 
expression in HCC tissues (14). However, no data exist concerning the association of activated STAT3 with EMT in HCC cells. Whether STAT3 binds the Twist promoter and mediates its biological functions in HCC is also elusive. We carried out the present study to discover whether STAT3 mediates the EMT process, promotes HCC invasion and migration, and whether this effect is directly caused by the regulation of Twist expression in HCC cells.

\section{Materials and methods}

Cell culture. SMMC7721 cells (low metastatic human HCC cell line; Shanghai Cell Bank, Chinese Academy of Sciences, Shanghai, China) (15), MHCC97H cells (high metastatic human HCC cell line; Liver Cancer Institute of Zhongshan Hospital, Shanghai, China) (16) and HEK293T cells (Shanghai Cell Bank, Chinese Academy of Sciences) were used in the present study. Cells were cultured in Dulbecco's modified Eagle's medium (DMEM) with high glucose supplemented with $10 \%$ fetal bovine serum (FBS), $100 \mathrm{U} / \mathrm{ml}$ penicillin $\mathrm{G}$, and $50 \mu \mathrm{g} / \mathrm{ml}$ streptomycin at $37^{\circ} \mathrm{C}$ in a humidified atmosphere containing $5 \% \mathrm{CO}_{2}$ and $95 \%$ air.

Antibodies and reagents. Monoclonal antibodies against STAT3, E-cadherin, $\beta$-catenin, $\mathrm{N}$-cadherin, vimentin and $\beta$-actin, and a polyclonal antibody against Twist were obtained from Santa Cruz Biotechnology (Santa Cruz, CA, USA). A monoclonal antibody against phosphorylated STAT3 (p-STAT3, Tyr705) was obtained from Cell Signaling Technology (Beverly, MA, USA).

Plasmid construction. The STAT3 eukaryotic expression vector was chemically synthesized, constructed, sequenced and identified by Shanghai GeneChem Chemical Technology Co., Ltd. (GenBank ${ }^{\circledR}$ accession no. NM_003150). The upstream and downstream primers were: STAT3-F, 5'-TCCAACTTT GTGCCAATGGCCCAATGGAATCAGC-3' and STAT3-R, 5'-AATGCCAACTCTGTCCATGGGGGAGGTAGCGCA CT-3', with restriction sites of HindIII/XhoI, respectively. The primers were then cloned into the vector of GV142 (which was constructed by the Shanghai GeneChem Chemical Technology Co., Ltd.). Vectors of STAT3 small hairpin RNAs (shRNA) were also chemically synthesized, constructed, sequenced and identified by Shanghai GeneChem Chemical Technology Co., Ltd. (GenBank ${ }^{\circledR}$ accession no. NM_003150). Locations and nucleotide sequences of the 3 constructed coding regions were as follows: 1926-1944 (GCAGCAGCTGAACAACATG) followed by a 9-bp loop sequence of TTCAAGAGA, and the reverse complementary sequences (marked as STAT3SiRNA-I), 771-789 (CATCTGCCTAGATCGGCTA) also followed by the loop and the inverted repeat (STAT3-SiRNA-II) and 1929-1947 (GCAGCTGAACAACATGTCA) again followed by the loop and the inverted repeat (STAT3SiRNA-III). Then, these sequences were constructed into the GV102 vector by Shanghai GeneChem Chemical Technology Co., Ltd. Moreover, a negative control scrambled siRNA (TTCTCCGA ACGTGTCACGT) was used as a control.

The full-length promoter sequence of the wild-type Twist (Twist WT) (with restriction sites of NheI/HindIII) was chemically synthesized, constructed, sequenced, identified and cloned into the GV238 vector by the Shanghai GeneChem Chemical Technology Co., Ltd. According to the report of Cheng et al (12), we selected for study the second binding site among those closest to the initiation codon and which were likely to bind the Twist promoter. It was then treated with sitedirected mutagenesis, i.e., the sequence between -115 and -107 (which was TTCCTATAA) was replaced as AGAAATACT.

Construction of stable transfection HCC cells and the experimental groups. Frozen well-constructed Escherichia coli (E. coli) bacterial solutions with eukaryotic STAT3 vector expression and those transfected with the STAT3 RNA interference vectors were thawed and seeded onto bacteria culture plates containing $100 \mu \mathrm{g} / \mathrm{ml}$ ampicillin for a $16-\mathrm{h}$ culture inside a $37^{\circ} \mathrm{C}$ incubator. Monoclonal colonies were selected and cultured in Luria-Bertani (LB) liquid medium (containing $100 \mu \mathrm{g} / \mathrm{ml}$ ampicillin) on a $37^{\circ} \mathrm{C}, 200 \mathrm{rpm}$ shaker for $12 \mathrm{~h}$. Plasmids were extracted using the GoldHi EndoFree Plasmid Maxi Kit (Beijing Kangwei Century Biotech Co., Ltd., China) strictly following the manufacturer's instructions. The extracted plasmids were measured and adjusted by a UV spectrophotometer to a concentration of $20 \mathrm{nmol} / \mathrm{ml}$. Plasmids containing eukaryotic expression vectors of STAT3 and STAT3 RNA interference vectors (both $20 \mathrm{pmol}$ ) were diluted into the cDNA transfection buffer (final volume of $50 \mu \mathrm{l}$ ) by a 5-sec vortex. The $2.6 \mu \mathrm{l}$ transfection reagents were diluted into the cDNA transfection buffer (final volume of $50 \mu \mathrm{l}$ ) by a 10 -sec vortex. The well-diluted transfection reagents were added into the nucleic acid solution and cultured for $15 \mathrm{~min}$ under room temperature after a 3-sec vortex, and then the mixed solution was diluted by a $900 \mu 1$ culture medium. The cells were washed by sterile phosphate-buffered saline (PBS) after the original medium inside the culture plates was discarded. It was replaced by $900 \mu \mathrm{l}$ mixed solution, and then the cells were cultured in a $37^{\circ} \mathrm{C} / 5 \% \mathrm{CO}_{2}$ incubator for another $6 \mathrm{~h}$. Subsequently, we carried out a sequential culture replacement by antibiotic culture medium with $200 \mu \mathrm{g} / \mathrm{ml} \mathrm{G} 418$. Finally, for cell screening and construction, cells containing the STAT3 eukaryotic expression vector plasmid were cultured in DMEM containing $10 \% \mathrm{FBS}$ and $400 \mu \mathrm{g} / \mathrm{ml}$ G418. Cells with STAT3 RNA interference vectors were cultured in DMEM containing $10 \% \mathrm{FBS}$ and $2.5 \mu \mathrm{g} / \mathrm{ml}$ puromycin. Media were replaced every other day to observe the cell states. When all the control group cells died ( 10-14 days), the monoclonal cell lines were prepared after trypsinization and double dilution. When the monoclonal cell lines completely covered a 24 -well plate, they were identified and expanded in culture. In the present study, there were 3 groups in the stable transfection experiment of STAT3 overexpression: the blank control, GV142 transfection vector and STAT3 overexpression transfection vector groups, which were marked as control, GV142 and GV142/STAT3, respectively. There were 3 groups in the stable transfection experiment of STAT3 RNA interference: the blank control, GV102 transfection vector and STAT3 RNA interference recombinant plasmid groups, which were marked as control, GV102 and GV102/STAT3 SiRNA, respectively.

Quantitative real-time PCR. Total RNA was extracted from the cell lines using TRIzol reagent (Invitrogen, USA) according to the manufacturer's instructions. mRNA quality 
was evaluated by the OD260/OD280 ratio, and samples were used only when the ratio was between 1.8 and 2.0. cDNA was synthesized with oligo(dT) $)_{18}$ from $1 \mathrm{mg}$ of RNA using the Revert Aid First Strand cDNA Synthesis Kit (Invitrogen). Gene-specific primer sequences were designed as follows: STAT3 (sense, 5'-CTCTGCCGGAGAAACAGGATGG-3' and antisense, 5'-ACTCTCAATCCAAGGGGCCA-3'); Twist (sense, 5'-TTCTGCCTCTTTCGAGCACC-3' and antisense, 5'-TACAACGACCCAGTCTGACG-3'); E-cadherin (sense, 5'-TCGCTTACACCATCCTCAGC-3' and antisense, 5'-GGAAACTCTCTCGGTCCAGC-3'); $\beta$-catenin (sense, 5'-ACCACAAGCAGAGTGCTGAA-3' and antisense, 5'-GCTTGCATTCCACCAGCTTC-3'); N-cadherin (sense, 5'-AACAGCAACGACGGGTTAGT-3' and antisense, 5'-CAGACACGGTTGCAGTTGAC-3'); and vimentin (sense, 5'-AGGCGAGGAGAGCAGGATTT-3' and antisense, 5'-AGTGGGTATCAACCAGAGGGA-3'). To standardize RNA quality control, expression of glyceraldehyde-3-phosphate dehydrogenase (GAPDH) in each sample was quantified using the primer set 5'-GCCGCATCTTCTTTTGCGTC-3' (sense) and 5'-TACGACCAAATCCGTTGACTCC-3' (antisense). Cycling parameters were as follows: initial denaturation $\left(95^{\circ} \mathrm{C}, 10 \mathrm{~min}\right)$, followed by 40 cycles of denaturation $\left(95^{\circ} \mathrm{C}\right.$, $15 \mathrm{sec})$ and annealing $\left(60^{\circ} \mathrm{C}, 1 \mathrm{~min}\right)$. PCR products were quantified via melting curve analysis at $84^{\circ} \mathrm{C}$. All reactions were performed in triplicate and normalized to GAPDH to ensure a uniform amount of RNA template.

Western blot analysis. SMMC7721 and MHCC97H cells were lysed for protein extraction. The protein concentration was measured using a Bicinchoninic Acid Protein Assay Reagent kit (Qiagen). The total cell lysates were separated by sodium dodecyl sulfate-polyacrylamide gel electrophoresis and then transferred to polyvinylidene difluoride membranes (Millipore). After brief incubation with 5\% non-fat milk, the membranes were probed with STAT3, p-STAT3, Twist, E-cadherin, $\beta$-catenin, $\mathrm{N}$-cadherin, vimentin and $\beta$-actin primary antibodies at $4{ }^{\circ} \mathrm{C}$ overnight. After washing, the membranes were incubated with the secondary peroxidaseconjugated antibody for $1 \mathrm{~h}$ at room temperature. Protein bands were visualized using an enhanced chemiluminescence detection kit (Amersham Pharmacia Biotech, Piscataway, NJ, USA). The densitometry for each band was measured with Quantity One Software (National Institutes of Heath, USA). All reactions were performed in triplicate and the values were normalized according to internal standard $\beta$-actin expression.

Immunocytochemical analysis. The fixed cells in 6-well plates were washed with PBS, followed by fixation with $4 \%$ paraformaldehyde for $20 \mathrm{~min}$ at $4^{\circ} \mathrm{C}$. Then, the cells were permeabilized with $0.1 \%$ Triton $\mathrm{X}-100$ for $10 \mathrm{~min}$ at room temperature. After being blocked with $10 \%$ goat serum at room temperature for $10 \mathrm{~min}$, the cells were incubated with STAT3 (1:100), p-STAT3 (1:50), Twist (1:100), E-cadherin (1:100), $\beta$-catenin (1:100), $\mathrm{N}$-cadherin (1:100), vimentin (1:100) and $\beta$-actin $(1: 100)$ at $4^{\circ} \mathrm{C}$ overnight. After washing, the cells were reacted with the corresponding secondary antibody at $37^{\circ} \mathrm{C}$ for $15 \mathrm{~min}$. Finally, they were incubated in PBS containing diaminobenzidine (DAB) for $5 \mathrm{~min}$. Microscopy was employed to visualize targeted protein staining. For assessment of STAT3, p-STAT3 and Twist expression, the cells were considered positive when their cytoplasm and/or nuclei exhibited yellow or brown staining. For assessment of E-cadherin and $\beta$-catenin expression, cells were considered positive when their membranes exhibited yellow or brown staining. For assessment of $\mathrm{N}$-cadherin and vimentin expression, cells were considered positive when their cytoplasm exhibited yellow or brown staining.

Dual-luciferase reporter assay. A suspension of HEK293T cells in logarithmic growth phase was prepared after trypsinization. Then, the cell suspensions $\left(1 \times 10^{4}\right.$ cells/well $)$ were seeded onto 24 -well plates and cultured in a $37^{\circ} \mathrm{C} / 5 \% \mathrm{CO}_{2}$ incubator until they reached a cell fusion degree of $\sim 80 \%$. Transfection was performed using Lipofectamine 2000 (Invitrogen), strictly following the manufacturer's instructions. This experiment included 4 transfection groups: the group with $1.0 \mu \mathrm{g}$ plasmid of the Twist WT promoter (this recombinant plasmid has firefly luciferase genes), group with $1.0 \mu \mathrm{g}$ plasmid of the Twist MT promoter, co-transfection group of GV142/STAT3 (concentrations of $0.1,0.5,1.0,2.0$ and $4.0 \mu \mathrm{g}$ ) and Twist WT, and co-transfection group of GV142/STAT3 (concentrations of 0.1, 0.5, 1.0, 2.0 and $4.0 \mu \mathrm{g}$ ) and Twist MT. All 4 groups were transfected with the Renilla Luciferase reporter genes. Transfection efficiency was assessed $24 \mathrm{~h}$ after transfection based on fluorescence-labeled gene expression levels according to the manufacturer's instructions (Dual-Glo $^{\mathrm{TM}}$ Luciferase Assay kit; cat no. E2920; Promega, Madison, WI, USA). Values of firefly and Renilla luciferase in each group were detected using the single transfection group values of Twist WT $(1.0 \mu \mathrm{g})$ and Twist MT $(1.0 \mu \mathrm{g})$ as the baselines. The statistical values of the firefly and Renilla luciferase values were measured minus the corresponding baselines. The firefly and Renilla luciferase value ratios produced the relative luminescence unit (RLU) value. All RLU values were normalized using the single transfection group values of Twist WT $(1.0 \mu \mathrm{g})$ and Twist MT $(1.0 \mu \mathrm{g})$ as 1 , respectively. The corresponding ratios (marked as STAT3/Twist WT and STAT3/ Twist MT) were calculated. This experiment was repeated thrice.

Cell proliferation assay. All SMMC7721 and MHCC97H cells were trypsinized into cell suspensions at a concentration of $1 \times 10^{4} / \mathrm{ml}$ when they were in the logarithmic growth phase. The cell suspensions were seeded onto 96-well plates (100 $\mu \mathrm{l} /$ well), and then the cells were diluted to a single cell using the doubling dilution method. Cell morphologies of each group were observed on the next day under an inverted microscope. The monoclonal cells were marked and photographed (this was the cell number on day 0). Culture medium (DMEM + 10\% FBS) was changed every other day. Cells under close observation were photographed on days 3 and 6 to calculate the proliferated cell numbers. The cell proliferation was also examined by 3-(4,5-dimethylthiazol-2-yl)-2,5-diphenyltetrazolium bromide (MTT) assay: cells were seeded in $100 \mathrm{~mm}^{2}$ tissue culture plates at a density of $2-3 \times 10^{6}$ cells/well. After culture for 3 and 6 days, respectively, the cells were incubated with MTT (5 $\mu \mathrm{g} / \mathrm{ml})$ for $4 \mathrm{~h}$. Optical density (OD) was read with Bio-Rad instruments (Bio-Rad, Hercules, CA, USA) at a wavelength of $490 \mathrm{~nm}$. The conditions of cell proliferation 

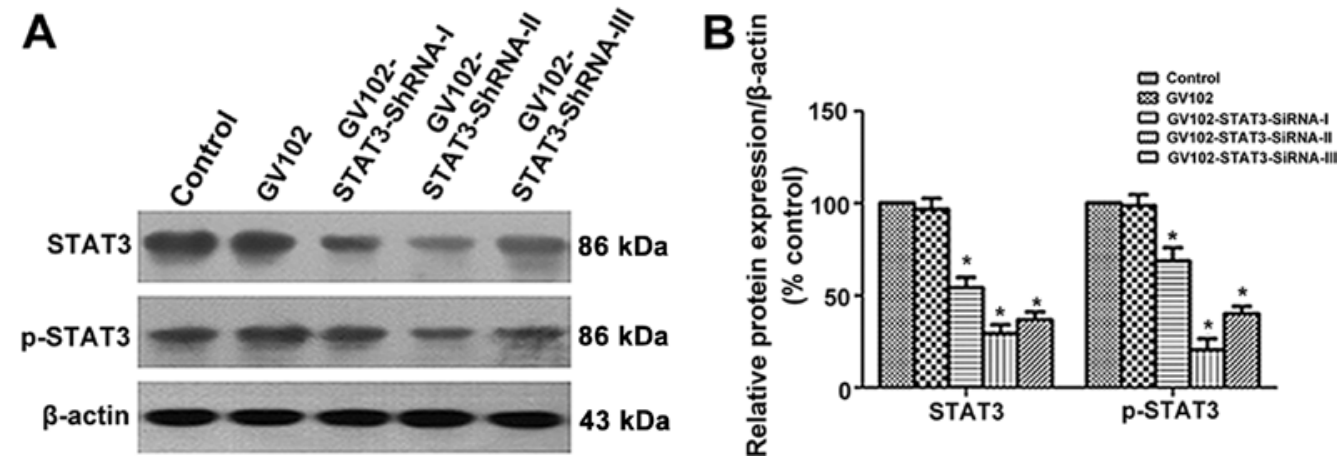

Figure 1. Effects of STAT3-specific shRNA expression vectors on STAT3 and p-STAT3 expression in HCC cells. (A) STAT3 and p-STAT3 protein levels were determined by western blotting in MHCC97H cells after transient transfection of different shRNA expression vectors (STAT3-SiRNA-I, STAT3-SiRNA-II and STAT3-SiRNA-III). (B) Semi-quantitative analyses of the relative levels of STAT3 and p-STAT3 protein expression observed with the $\beta$-actin internal controls in MHCC97H cells (group data represent mean $\pm \mathrm{SD}$ ). ${ }^{*} \mathrm{P}<0.01$, compared to the control group. STAT3, signal transducer and activator of transcription 3.

were denoted by the proliferative rate $(P R) . P R=(O D$ value of treatment group/OD value of control group) $\mathrm{x} 100 \%$. All experiments were repeated thrice.

Cell invasion assay. The cell invasive assay was performed using a 24-well Transwell chamber (Costar, USA). Cells were seeded in $100 \mathrm{~mm}^{2}$ tissue culture plates at a density of $2-3 \times 10^{6}$ cells/well and incubated for $24 \mathrm{~h}$. Then, cells $\left(1 \times 10^{4}\right)$ were detached and seeded in the upper chamber of an $8-\mu \mathrm{m}$ pore size insert precoated with Matrigel (BD, USA) and cultured in serum-free medium for $24 \mathrm{~h}$. Cells were allowed to migrate toward the medium containing $10 \%$ FBS in the bottom chamber. The non-migratory cells on the upper membrane surface were removed with a cotton tip, and the migratory cells that attached to the lower membrane surface were fixed with $4 \%$ paraformaldehyde and stained with hematoxylin. Invaded cells were stained, photographed digitally and quantified. Data presented are representative of three individual wells.

Cell migration assay. Scratch marks were made with a marker pen at the back of a 6-well culture plate. When the cells were in the logarithmic growth phase, they were trypsinized into cell suspensions at a concentration of $1 \times 10^{5} / \mathrm{ml}$. The cell suspensions were seeded onto 6 -well plates $(2 \mathrm{ml} /$ well $)$ for continuous culture. Medium was changed on the next day. Cell morphology and growing statuses were under close observation. When the cells completely covered the culture plate, scratch marks were made vertically toward the plate by a $10-\mu 1$ tips along the previous mark lines. Cell migration assessment was conducted after three sterile PBS washings and serumfree medium replacement. Then, the cells were photographed as the baseline $(0 \mathrm{~h})$. The cells were photographed again $24 \mathrm{~h}$ later, and the cell migration was calculated as follows: Cell migration $=($ width of the scratch mark at $0 \mathrm{~h}-$ width of the scratch mark at $24 \mathrm{~h}$ )/width of the scratch mark at $0 \mathrm{~h}$. All cell migration values were normalized using the value of the control as 1 , and the corresponding ratios were calculated. This experiment was repeated thrice.

Statistical analysis. All statistical analyses were performed using SPSS 13.0 software for Windows (SPSS, Inc., Chicago, IL, USA). In the cell culture tests, data are expressed as means \pm standard deviation (SD), and they were pooled from at least three independent experiments to avoid possible biases. Differences between two groups were tested using the Student's t-test. Differences between multiple groups were tested using analysis of variance (ANOVA). For the above comparisons, two-tailed $\mathrm{P}$-values $<0.05$ were considered to indicate statistically significant results.

\section{Results}

Selection of the most effective STAT3-specific shRNA expression vector targeting STAT3. To evaluate the comparative silencing effects of the STAT3-specific shRNA expression vectors on STAT3 expression, MHCC97H cells were transfected transiently with the recombinant plasmids. The STAT3 and p-STAT3 protein levels were detected by western blotting $24 \mathrm{~h}$ after shRNA expression vector transfection. Our results showed that transfection of STAT3-SiRNA-I, STAT3-SiRNA-II and STAT3-siRNA-III significantly reduced STAT3 and p-STAT3 expression in the MHCC97H cells, yet negative control transfection did not reduce STAT3 and p-STAT3 expression. The gene silencing effect was nearly 45.7, 70.5 and $63.2 \%$, respectively, in the STAT3-SiRNA-I, STAT3-SiRNA-II and STAT3-SiRNA-III groups when compared to the control. Noticeably, the most obvious gene silencing effect was observed in the STAT3-siRNA-2 group (Fig. 1A and B). Thus, we chose STAT3-siRNA-2 (hereafter referred to as STAT3 SiRNA) for subsequent stable transfection in the present study.

Role of STAT3 in EMT molecular marker changes in HCC cells. We determine whether STAT3 and its activated form could induce specific molecular changes consistent with EMT in the SMMC7721 and MHCC97H cells. We first succeeded in constructing SMMC7721 cell lines that stably overexpressed STAT3 (GV142/STAT3 cells) and MHCC97H cell lines that stably silenced STAT3 (GV102/STAT3 SiRNA cells) expression. We then examined the expression of epithelial markers E-cadherin and $\beta$-catenin, and mesenchymal markers $\mathrm{N}$-cadherin and vimentin, using real-time PCR, western blotting and immunocytochemical methods. We determined that STAT3 and p-STAT3 expression levels in the SMMC7721 cells of the GV142/STAT3 group were significantly higher than those in the control and GV142 group $(\mathrm{P}<0.01$; Figs. $2 \mathrm{~A}-\mathrm{C}$ and $3 \mathrm{~A})$, indicating successful STAT3 overexpression. E-cadherin 

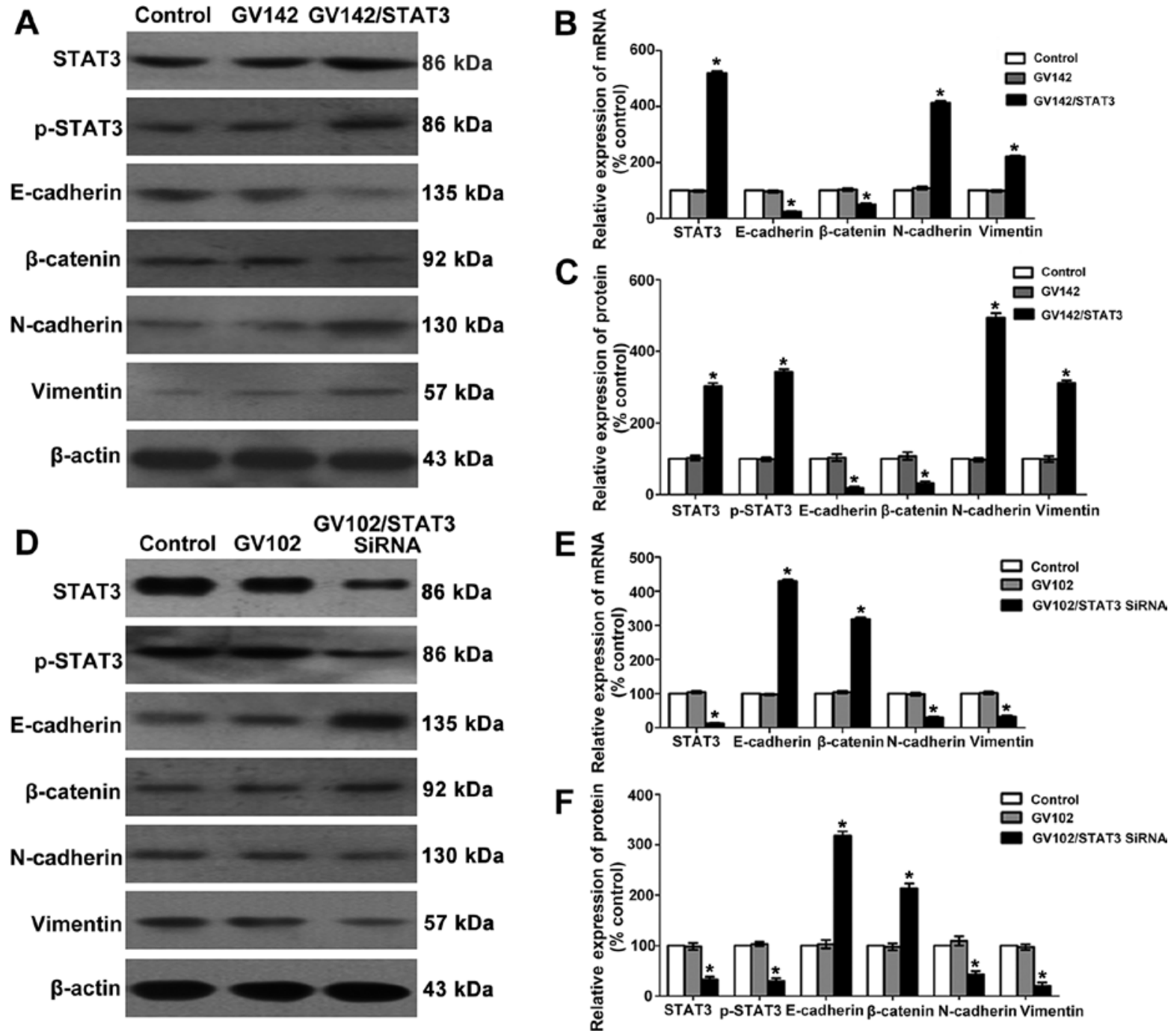

Figure 2. Effect of STAT3 on molecular changes consistent with EMT in HCC cells. (A) STAT3, p-STAT3, E-cadherin, $\beta$-catenin, N-cadherin and vimentin protein levels were determined by western blotting in SMMC7721 cells. (B) Quantitative real-time PCR analyses of the relative levels of STAT3, E-cadherin, $\beta$-catenin, $\mathrm{N}$-cadherin and vimentin mRNA expressions observed with the GAPDH internal controls in SMMC7721 cells (group data represent mean \pm SD) ${ }^{*} \mathrm{P}<0.01$, compared to the control group. (C) Semi-quantitative analyses of the relative levels of STAT3, p-STAT3, E-cadherin, $\beta$-catenin, N-cadherin and vimentin protein expression observed with the $\beta$-actin internal controls in SMMC7721 cells (group data represent mean \pm SD). ${ }^{*} \mathrm{P}<0.01$, compared to the control group. (D) STAT3, p-STAT3, E-cadherin, $\beta$-catenin, $\mathrm{N}$-cadherin and vimentin protein levels were determined by western blotting in MHCC97H cells. (E) Quantitative real-time PCR analyses of the relative levels of STAT3, E-cadherin, $\beta$-catenin, $\mathrm{N}$-cadherin and vimentin mRNA expression observed with the GAPDH internal controls in MHCC97H cells (group data represent mean $\pm \mathrm{SD}$ ). "P<0.01, compared to the control group. (F) Semi-quantitative analyses of the relative levels of STAT3, p-STAT3, E-cadherin, $\beta$-catenin, N-cadherin and vimentin protein expression observed with the $\beta$-actin internal controls in MHCC 97H cells (group data represent mean \pm SD). "P<0.01, compared to the control group. STAT3, signal transducer and activator of transcription 3; EMT, epithelial-to-mesenchymal transition.

and $\beta$-catenin expression levels were significantly reduced, while those of $\mathrm{N}$-cadherin and vimentin were significantly increased, as well as the elevated STAT3 and p-STAT3 expression levels (compared to the control and GV142 group, $\mathrm{P}<0.01$; Figs. 2A-C and 3A). Additionally, we found that STAT3 and p-STAT3 expression levels in the MHCC97H cells of the STAT3-siRNA group were significantly lower than those in the control and GV102 group ( $\mathrm{P}<0.01$; Figs. 2D-F and 3B). This indicated effective STAT3 knockdown. E-cadherin and $\beta$-catenin expression levels were significantly increased, while those of $\mathrm{N}$-cadherin and vimentin were significantly lowered, as well as the reduced STAT3 and p-STAT3 expression levels (compared to the control and GV102 group, $\mathrm{P}<0.01$; Figs. 2D-F and 3B). These results suggest that STAT3 may contribute to EMT initiation and progression in HCC cells.
Role of STAT3 in cell proliferation, invasion and migration in HCC cells. Results from various studies indicate that abnormal expression or enhanced activity of STAT3 is closely associated with tumor activities such as proliferation, differentiation and apoptosis $(17,18)$. Therefore, we first confirmed the effects of the existence and activation of STAT3 on HCC proliferation with a cell proliferation assay. Then, since EMT induces tumor cell migration and invasion, we further assessed the relationship between STAT3 and EMT-induced HCC cell migration and invasion using cell invasion and cell migration assays. The cell proliferation assay indicated that STAT3 and p-STAT3 overexpression significantly promoted SMMC7721 cell proliferation (compared to the control and the GV142 group, P<0.01; Fig. 4A-C), while STAT3 and p-STAT3 knockdown significantly reduced MHCC $97 \mathrm{H}$ cell proliferation (compared 

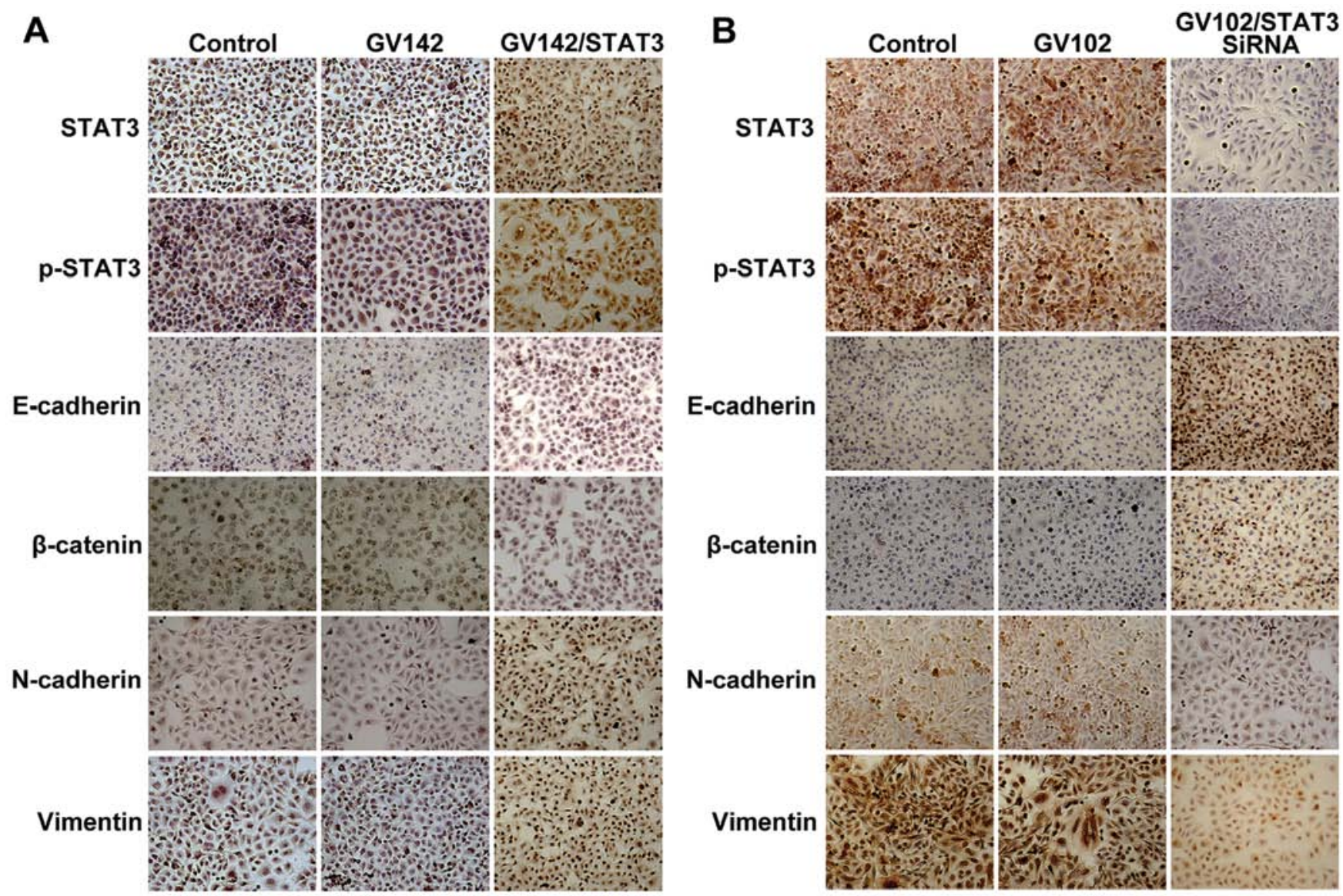

Figure 3. Effect of STAT3 on molecular changes consistent with EMT in HCC cells. (A) STAT3, p-STAT3, E-cadherin, $\beta$-catenin, N-cadherin and vimentin protein levels were detected by immunocytochemistry in SMMC7721 cells (magnification, x200). STAT3 and p-STAT3 expression was observed mainly in the cytoplasm and/or nuclei in a focal or scattered pattern. E-cadherin and $\beta$-catenin expression was mainly in the membranes in an evenly scattered manner. $\mathrm{N}$-cadherin and vimentin expression was mainly observed in the cytoplasm in a focal or scattered pattern. Immunocytochemical analyses indicated that E-cadherin and $\beta$-catenin expression levels were significantly reduced while those of $\mathrm{N}$-cadherin and vimentin were significantly increased, as well as the elevated STAT3 and p-STAT3 expression levels. (B) STAT3, p-STAT3, E-cadherin, $\beta$-catenin, N-cadherin and vimentin protein levels were detected by immunocytochemistry in MHCC97H cells (magnification, $\mathrm{x} 200$ ). Immunocytochemical analyses indicated that E-cadherin and $\beta$-catenin expression levels were significantly increased while those of $\mathrm{N}$-cadherin and vimentin were significantly decreased, as well as the reduced STAT3 and p-STAT3 expression levels. STAT3, signal transducer and activator of transcription 3; EMT, epithelial-to-mesenchymal transition.

to the control and the GV102 group, P<0.05; Fig. 4D-F). Cell invasion and cell migration assays indicated that STAT3 overexpression significantly promoted the in vitro invasion and migration of the SMMC7721 cells (compared to the control and the GV142 group, $\mathrm{P}<0.01$; Figs. $5 \mathrm{~A}$ and $\mathrm{B}$, and $6 \mathrm{~A}$ and $\mathrm{B}$ ), while STAT3 knockdown significantly reduced the in vitro invasion and migration of the MHCC $97 \mathrm{H}$ cells (compared to the control and the GV102 group, $\mathrm{P}<0.01$; Figs. $5 \mathrm{C}$ and $\mathrm{D}$, and $6 \mathrm{C}$ and $\mathrm{D})$.

Effect of STAT3 on Twist expression in HCC cells. The well-recognized key transcription factors involved in EMT regulation include: ZEB1, Snail, SIP1 and Twist. As a highly conserved member of the basic helix-loop-helix (bHLH) protein family, Twist has been the most frequently studied EMT-regulating factor in recent years and plays an important role in embryonic development. Additionally, as a key EMT-regulating factor, it also has significant influence on tumor invasion (19). Lo et al (11) and Cheng et al (12) found that STAT3 activation induced EMT occurrence in breast cancer via Twist upregulation. To understand whether or not
Twist is involved in the EMT induced by STAT3 activation in HCC cells, we first detected the effects of altered STAT3 and p-STAT3 expression levels via real-time PCR, western blotting and immunocytochemistry. The results indicated that Twist expression levels were significantly increased or decreased following the elevation or reduction of STAT3 and p-STAT3 expression levels (compared to the control and the GV142 group, $\mathrm{P}<0.01$, Figs. $7 \mathrm{~A}-\mathrm{C}$ and $8 \mathrm{~A}$; compared to the control and the GV102 group, $\mathrm{P}<0.01$, Figs. 7D-F and $8 \mathrm{~B}$, respectively). To further explore whether or not STAT3 could mediate the Twist promoter transcriptional activity via binding with it, we identified the correlations between the two using the dualluciferase reporter assay. This revealed that the RLU value of the STAT3/Twist WT group was increased with increasing concentrations of GV142/STAT3, while the RLU value of the STAT3/Twist MT group remained unchanged. The difference between the two groups was significant $(\mathrm{P}<0.05$ and $\mathrm{P}<0.01$, Fig. 9A and B). The above results revealed that: i) STAT3 could bind the Twist WT promoter and promote Twist expression; ii) when the binding site was mutated, STAT3 barely binded Twist, indicating that this binding site (the second closest to 

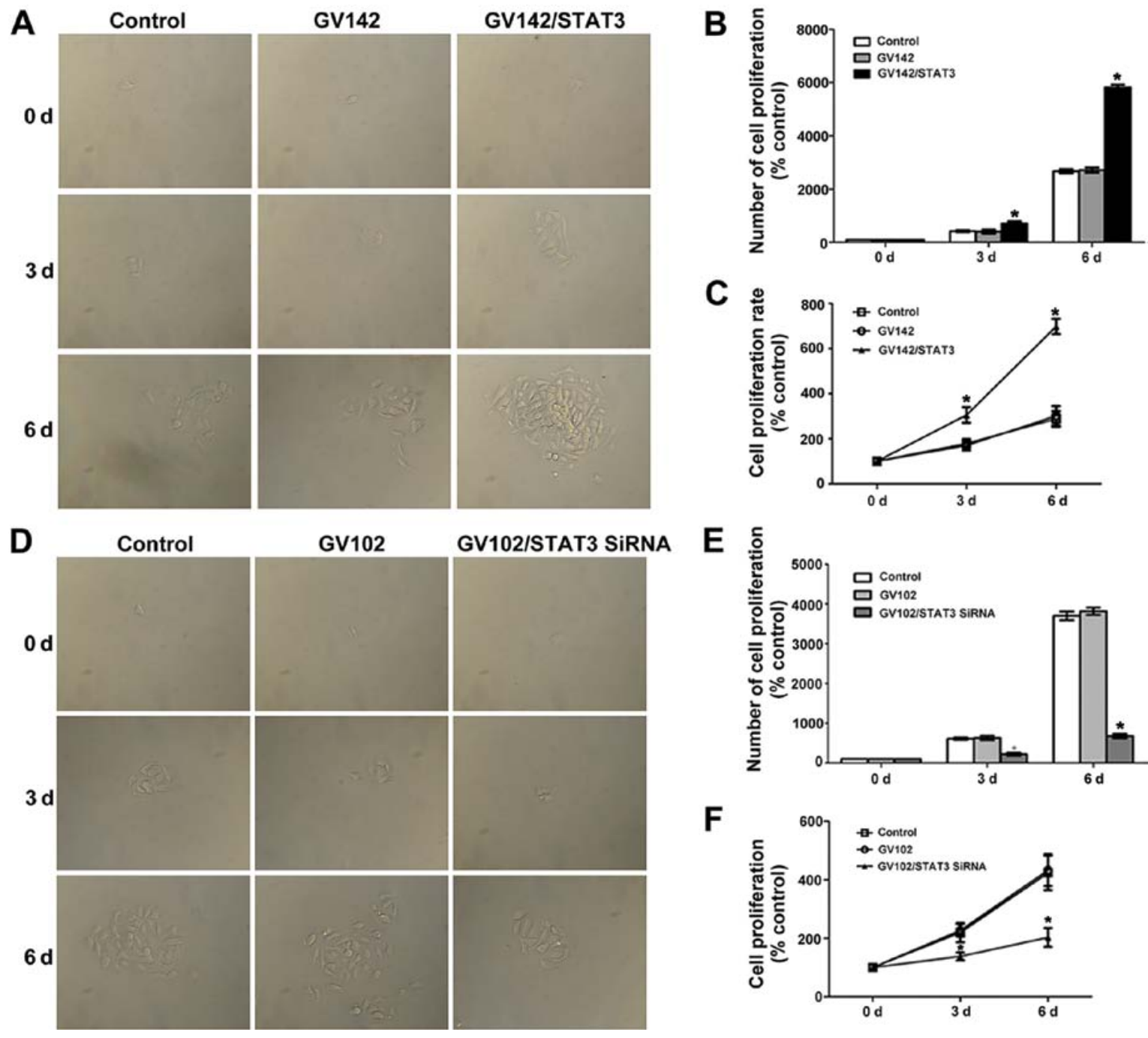

Figure 4. Effect of STAT3 on the cell proliferation of HCC cells. (A) Cell proliferation was determined by the doubling dilution method in SMMC7721 cells under an inverted microscope (magnification, $\mathrm{x} 200$ ). (B) Quantitative analyses of cell proliferation in SMMC7721 cells (group data represent mean \pm SD). ${ }^{*} \mathrm{P}<0.01$, compared to the control group. (C) Cell proliferation was detected by the MTT method in SMMC7721 cells and the proliferative rate was calculated and compared (group data represent mean $\pm \mathrm{SD}$ ). $\mathrm{P}<0.01$, compared to the control group. (D) Cell proliferation was determined by the doubling dilution method in MHCC97H cells under an inverted microscope (magnification, x200). (E) Quantitative analyses of cell proliferation in MHCC97H cells (group data represent mean $\pm \mathrm{SD}$ ). ${ }^{*} \mathrm{P}<0.01$, compared to the control group. (F) Cell proliferation was detected by the MTT method in MHCC97H cells and the proliferative rate was calculated and compared (group data represent mean $\pm \mathrm{SD}$ ). ${ }^{*} \mathrm{P}<0.01$, compared to the control group. STAT3, signal transducer and activator of transcription 3.
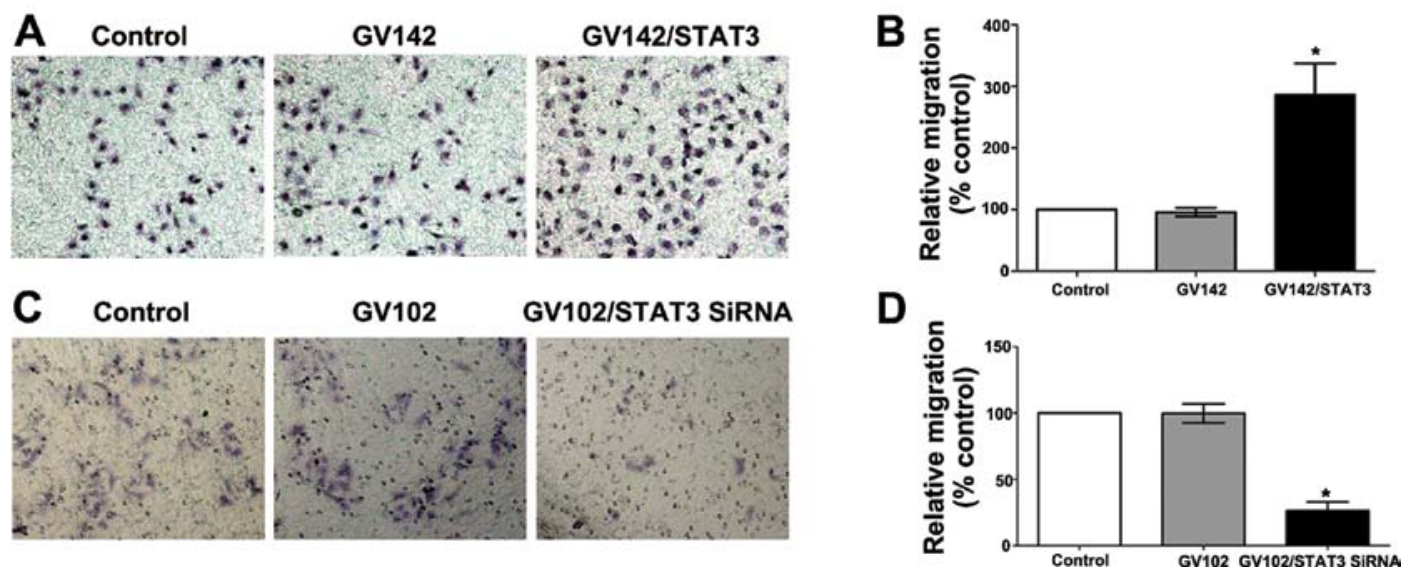

Figure 5. Effect of STAT3 on the cell invasion of HCC cells. (A) Representative images of cells that migrated to the bottom of the Transwell culture insert in SMMC7721 cells (hematoxylin staining, x200). (B) Quantitative analyses of cell invasion in SMMC7721 cells (group data represent mean \pm SD). "P<0.01, compared to the control group. (C) Representative images of cells that migrated to the bottom of the Transwell culture insert in MHCC97H cells (hematoxylin staining, x200). (D) Quantitative analyses of cell invasion in MHCC97H cells (group data represent mean \pm SD). " $\mathrm{P}<0.01$, compared to the control group. STAT3, signal transducer and activator of transcription 3. 
A Control

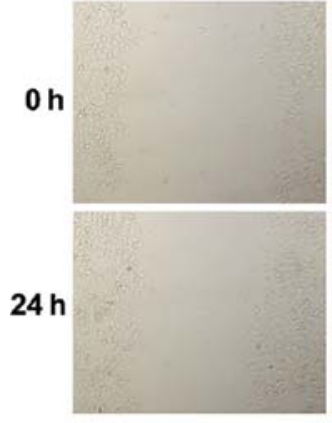

C

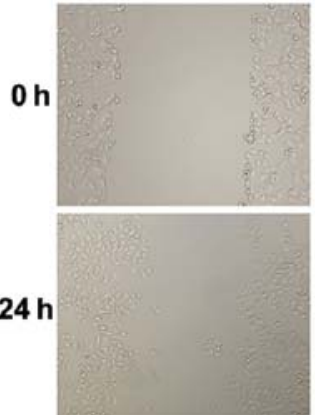

GV142

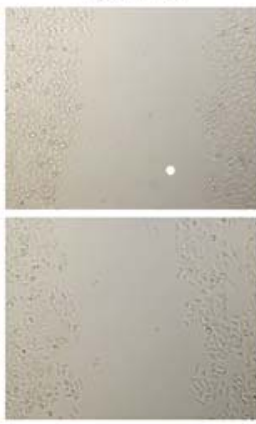

GV102
GV142/STAT3
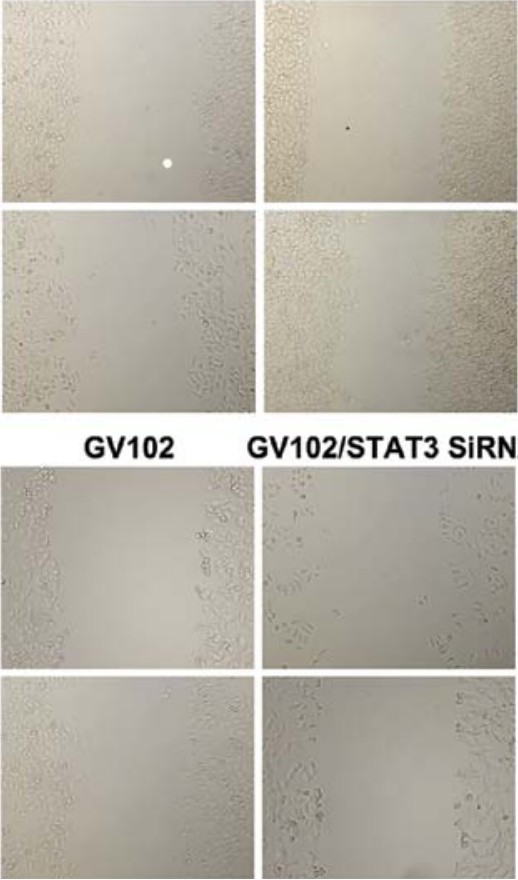

GV102/STAT3 SIRNA

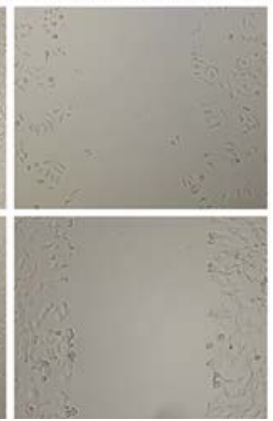

B

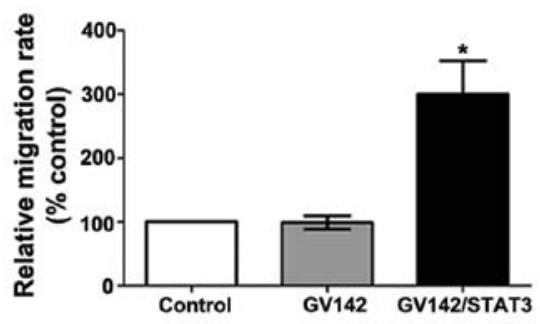

D

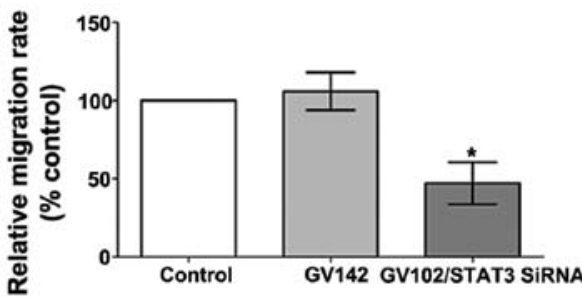

Figure 6. Effect of STAT3 on the cell migration of HCC cells. (A) Representative fields (magnification, x100) of cell migration in SMMC7721 cells $24 \mathrm{~h}$ after being scratched. (B) Quantitative analyses of the cell migration rate in SMMC7721 cells (group data represent mean \pm SD). "P<0.01, compared to the control group. (C) Representative fields (magnification, x100) of cell migration in MHCC97H cells $24 \mathrm{~h}$ after being scratched. (D) Quantitative analyses of the cell migration rate in MHCC97H cells (group data represent mean $\pm \mathrm{SD}$ ). " $\mathrm{P}<0.01$, compared to the control group. STAT3, signal transducer and activator of transcription 3.
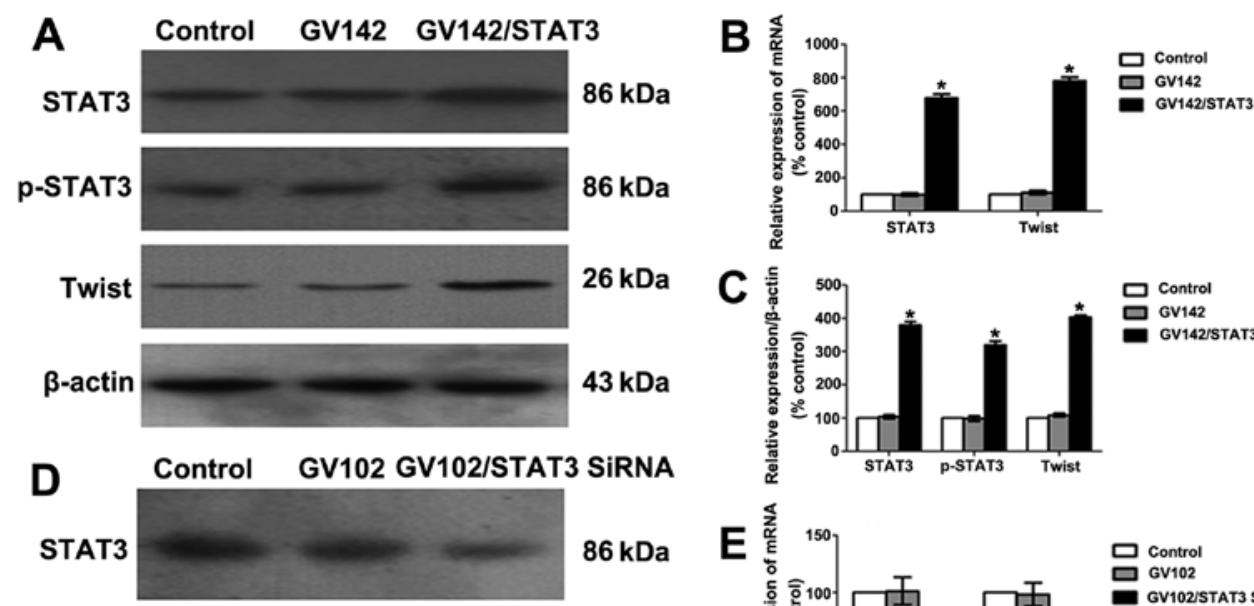

C
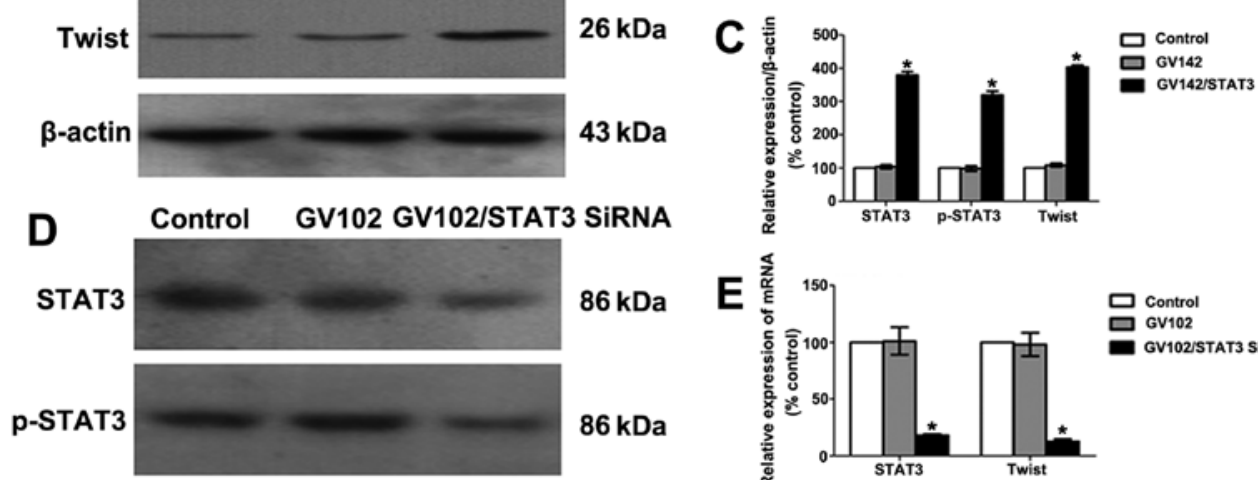

$86 \mathrm{kDa}$
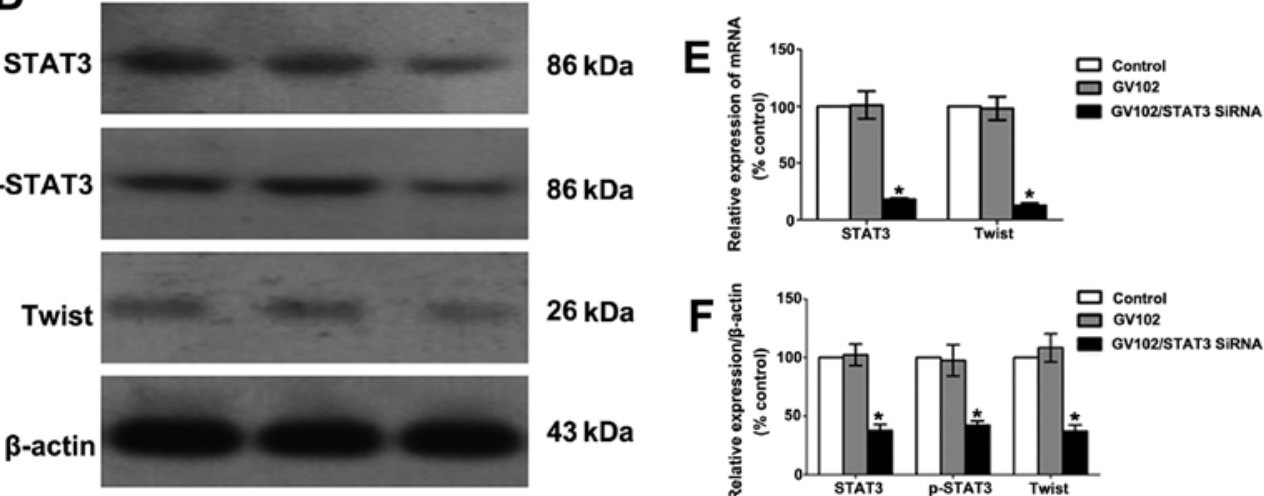

$26 \mathrm{kDa}$

$43 \mathrm{kDa}$

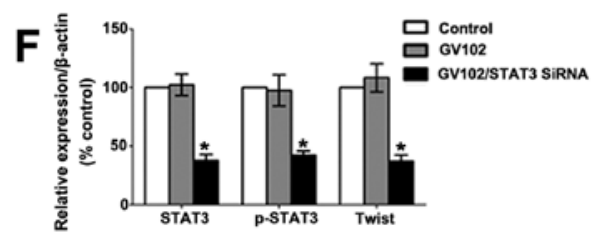

Figure 7. Effect of STAT3 on Twist expression in HCC cells. (A) STAT3, p-STAT3 and Twist protein levels were determined by western blotting in SMMC7721 cells. (B) Quantitative real-time PCR analyses of the relative levels of STAT3 and Twist mRNA expression observed with the GAPDH internal controls in SMMC7721 cells (group data represent mean \pm SD). ${ }^{*} \mathrm{P}<0.01$, compared to the control group. (C) Semi-quantitative analyses of the relative levels of STAT3, p-STAT3 and Twist protein expression observed with the $\beta$-actin internal controls in SMMC7721 cells (group data represent mean \pm SD). ${ }^{*} \mathrm{P}<0.01$, compared to the control group. (D) STAT3, p-STAT3 and Twist protein levels were determined by western blotting in MHCC97H cells. (E) Quantitative real-time PCR analyses of the relative levels of STAT3 and Twist mRNA expression observed with the GAPDH internal controls in MHCC97H cells (group data represent mean $\pm \mathrm{SD}$ ). ${ }^{*} \mathrm{P}<0.01$, compared to the control group. (F) Semi-quantitative analyses of the relative levels of STAT3, p-STAT3 and Twist protein expression observed with the $\beta$-actin internal controls in MHCC97H cells (group data represent mean \pm SD). ${ }^{*} \mathrm{P}<0.01$, compared to the control group. STAT3, signal transducer and activator of transcription 3. 

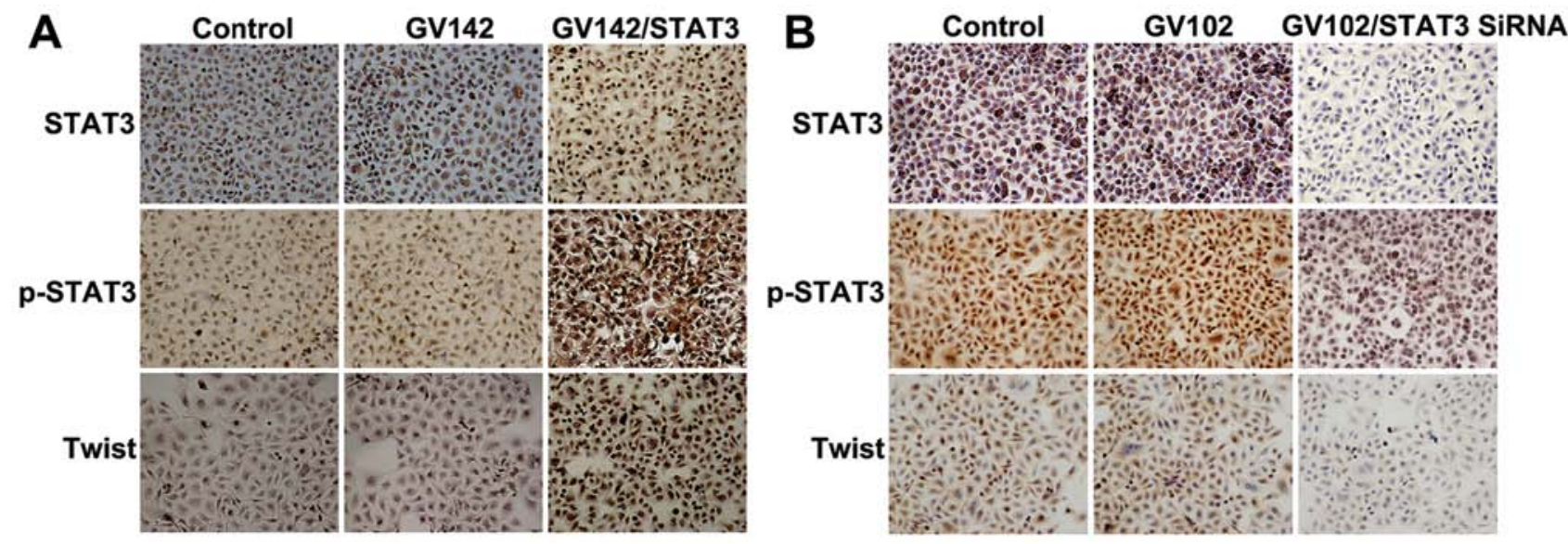

Figure 8. Effect of STAT3 on Twist expression in HCC cells. (A) STAT3, p-STAT3 and Twist protein levels were detected by immunocytochemistry in SMMC7721 cells (magnification, x200). STAT3, p-STAT3 and Twist expression was observed mainly in the cytoplasm and/or nuclei in a focal or scattered pattern. Immunocytochemical analyses indicated that the Twist expression level was significantly increased as well as the elevated STAT3 and p-STAT3 expression levels. (B) STAT3, p-STAT3 and Twist protein levels were detected by immunocytochemistry in MHCC97H cells (magnification, x200). Immunocytochemical analyses indicated that the Twist expression level was significantly lowered as well as the reduced STAT3 and p-STAT3 expression levels. STAT3, signal transducer and activator of transcription 3.

A

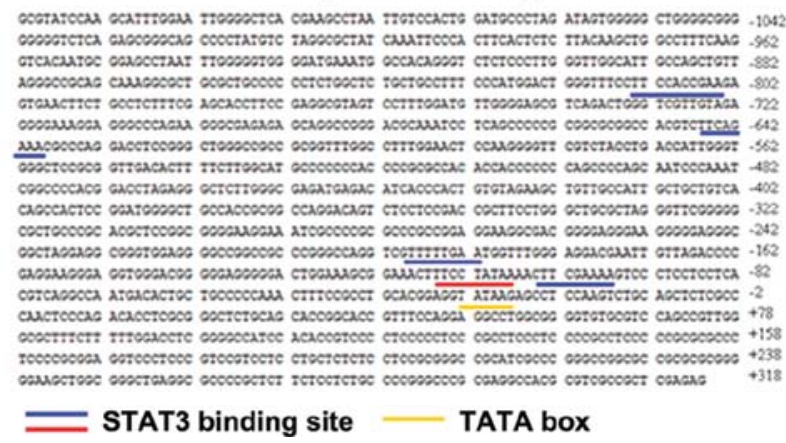

B

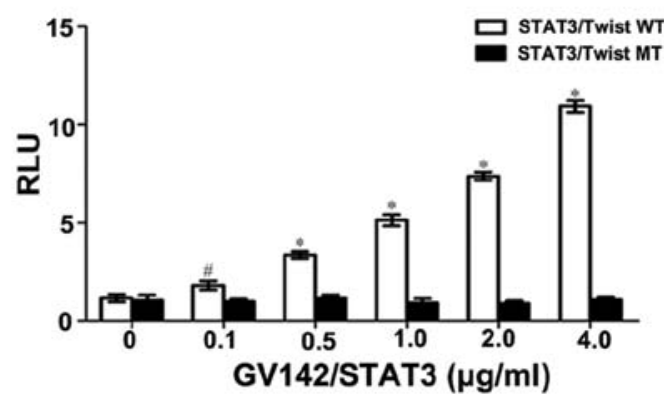

Figure 9. Effect of STAT3 on Twist expression in HCC cells. (A) Five STAT3 binding sites exist in the human Twist promoter region, which was indicated with blue and red underlines in the full-length promoter sequence of Twist. The red underline indicates the second binding site among those closest to the initiation codon and which were likely to bind the Twist promoter; this was our main study object. The yellow underline indicates the TATA box. (B) The results indicate that the RLU value of the STAT3/Twist WT group increased with increasing concentrations of GV142/STAT3, while the RLU value of the STAT3/Twist MT group remained unchanged. The difference between the two groups was significant (group data represent mean \pm SD; ${ }^{\text {"P }}<0.05$, "P<0.01). STAT3, signal transducer and activator of transcription 3; RLU, relative luminescence unit.

the initiation codon) was the main binding site and played a dominant role in STAT3 and Twist binding; iii) STAT3 binding and Twist promoter were dose-dependent.

\section{Discussion}

Tumor metastasis often contributes to poor clinical outcome for HCC patients, whereas invasion is a key step that leads to HCC metastasis (3). Thus, it is necessary to explore the molecular mechanisms of HCC invasion. Increasing evidence shows that EMT, a process described first in embryogenesis, is a crucial event that mediates tumor progression. This includes promotion of tumor local invasion, spreading through the blood circulation and metastasis. Although some studies have investigated the possible role of EMT in $\operatorname{HCC}(20,21)$, the upstream signaling pathways that regulate EMT remain obscure. Presently, several studies have reported an association between STAT3 and EMT, which is mediated through E-cadherin repressors, the transcription factor Twist, estrogen- regulated zinc transporters LIV-1 in breast tumors and ZEB1 in colorectal cancers $(11,13,22,23)$. However, to date, this link has not been investigated in HCC, and the underlying molecular mechanisms remain elusive.

In the present study, we explored the roles of STAT3, Twist and EMT in HCC cell invasion and migration. We found that STAT3 activation may contribute to EMT in HCC through Twist mediation for the following reasons. i) STAT3 overexpression significantly reduced E-cadherin and $\beta$-cadherin and enhanced N-cadherin and vimentin expression in SMMC7721 cells. STAT3 knockdown significantly increased E-cadherin and $\beta$-cadherin and decreased $\mathrm{N}$-cadherin and vimentin expression in MHCC97H cells. ii) STAT3 overexpression markedly increased the invasion and migration abilities in SMMC7721 cells, and STAT3 downregulation significantly reduced $\mathrm{MHCC} 97 \mathrm{H}$ cell invasion and migration abilities. iii) A dual luciferase reporter assay indicated that STAT3 may bind to the second STAT3-binding motif on the Twist promoter proximal to the initial transcriptional site and then mediate its 
transcriptional activity. iv) As shown in our previous study, in HCC tissue samples, p-STAT3 was positively correlated with Twist expression, whereas Twist was negatively correlated with E-cadherin expression. p-STAT3, Twist or E-cadherin expression was significantly associated with HCC invasion and metastasis (14).

EMT refers to the transformation process of epithelial cells into mesenchymal cells, which is characterized by downregulation of epithelial markers such as E-cadherin/catenins and upregulation of mesenchymal markers such as N-cadherin and vimentin. This is followed by original extracellular matrix degeneration, and cell and matrix adhesion neogenesis, resulting in reduced cell-cell adhesion and greatly enhanced cell motility (14). Cell-cell and cell-matrix connections are realized by adhesion molecules. As an important member of the cadherin family, E-cadherin is the major adhesion molecule mediating cell-cell adhesion in epithelial cells, the normal function of which is critical to maintaining epithelial tissue and cell morphology. Reduced or silenced E-cadherin expression is believed to be the major EMT marker $(19,24,25)$. Since E-cadherin can hardly function alone, it usually binds proteins such as $\alpha$-catenin and $\beta$-catenin to form a complex, which then connects to the intracellular actin microfilaments and regulates cell morphology and movement. Downregulation, deletion and ectopy of E-cadherin, $\alpha$-catenin and $\beta$-catenin have been correlated with tumor behaviors during invasion and metastasis $(26,27)$. In the present study, we determined the effects of altered STAT3 and p-STAT3 expression on the expression of E-cadherin, $\alpha$-catenin and $\beta$-catenin. The results revealed that E-cadherin and $\beta$-catenin levels in SMMC7721 cells with STAT3 overexpression were significantly downregulated, while those of the MHCC $97 \mathrm{H}$ cells with silenced STAT3 were significantly upregulated. This indicated that STAT3 activation may induce HCC cell EMT. To further confirm EMT in HCC cells induced by STAT3 activation, we detected E-cadherin and $\beta$-catenin (epithelial marker) expression, and those of $\mathrm{N}$-cadherin and vimentin (mesenchymal markers). Downregulation of E-cadherin and upregulation of $\mathrm{N}$-cadherin are important EMT markers, which is a phenomenon termed the cadherin switch (28). In human squamous carcinoma cells, transfection with $\mathrm{N}$-cadherin was found to induce EMT and downregulate E-cadherin (29). Vimentin is an intermediate filament protein which plays a role in mesenchymal cell embryonic development and differentiation. Vimentin overexpression is often closely associated with tumor cell invasion and migration abilities (30,31). Our results indicated that in SMMC7721 cells with overexpressed STAT3, E-cadherin expression levels were significantly downregulated and expression levels of $\mathrm{N}$-cadherin and vimentin were upregulated. In MHCC97H cells with silenced STAT3 and E-cadherin expression levels were significantly upregulated, and those of $\mathrm{N}$-cadherin and vimentin were downregulated. These results indicate that STAT3 activation may induce the cadherin switch and mediate EMT in HCC cells.

Research has revealed that cell invasion and migration abilities with EMT occurrence are greatly enhanced, and EMT is believed to be the primary event in the tumor invasion and migration process (32). To understand the effect of EMT induced by STAT3 activation on HCC cell invasion and migration abilities, we first assessed the in vitro invasion ability in HCC cells with a Transwell cell invasion assay. The results indicated that in SMMC77211 cells with overexpressed STAT3, the invasion ability significantly increased, while in MHCC97H cells with silenced STAT3, the invasion ability was significantly reduced. Additionally, migration ability is one of the key factors that influences the tumor cell invasiveness. It is also an essential ability during the normal tissue invasion and transvascular activities. Multiple studies indicate that cell migration in tumors is closely correlated with their invasiveness, and highly invasive and metastatic tumor cells usually have strong migration ability (32). Our cell migration assay evaluated the in vitro migration of HCC cells. The results indicated that in SMMC77211 cells with overexpressed STAT3, the invasion ability was significantly increased, while in MHCC97H cells with silenced STAT3, the invasion ability was significantly reduced. These results imply that EMT induced by STAT3 activation significantly promotes in vitro HCC cell invasion and migration abilities.

Twist is a highly conserved member of the bHLH protein family. In recent years, growing evidence shows that Twist plays an important role in tumor development and EMT induction (33). The known important transcriptional factors to date include Twist, ZEB1, Snail and SIP1 (34). All are capable of recognizing the targeted genes, such as E-box of the E-cadherin promoter, and thus inhibit target gene transcription (33,35,36). In 2006, Lee et al (35) reported that Twist plays an important role in the HCC invasion process, and identified that Twist could inhibit the epithelial phenotype and induce mesenchymal phenotype changes. They found that either the cell morphology or expression levels of key molecules such as E-cadherin were significantly altered. These results support the conclusion that Twist induces EMT occurrence and promotes the HCC invasion process. Lo et al (11) and Cheng et al (12) found that p-STAT3 was positively correlated with Twist in breast cancer tissues, and activated STAT3 could specifically bind the Twist promoter and help induce the tumor invasion process. Based on the above data, to understand whether or not Twist is involved in STAT3-induced EMT in HCC cells, we first detected Twist expression via real-time PCR, western blotting and immunocytochemistry. The results revealed that in SMMC77211 cells with overexpressed STAT3, Twist expression levels were significantly upregulated, while in MHCC97H cells with silenced STAT3, they were significantly downregulated. Furthermore, we confirmed that STAT3 could mediate the transcriptional activity of the Twist promoter via targeted binding with it using the dual-luciferase reporter assay. Combined with our previous findings concerning the relationship among p-STAT3, Twist and E-cadherin in HCC tissue samples, we believe that STAT3 activation can mediate the Twist transcription and promote the EMT process in HCC. At least, this process is partially mediated by Twist. Our present results are consistent with the reports of Lo et al (11) and Cheng et al (12). Whether or not STAT3 promotes EMT in HCC via mediating other transcription factors (such as ZEB1) warrants further investigation.

In conclusion, we conclude that STAT3 activation is associated with EMT and subsequent induced HCC invasion and metastasis, which is possibly transcriptionally mediated by Twist. Our findings not only provide the molecular basis for the roles of STAT3, Twist and EMT in HCC invasion and 
metastasis, yet also offer novel targets for preventing and treating this morbid and lethal disease.

\section{Acknowledgements}

This study was supported by a grant from the National Nature Science Foundation of China (no. 81101877).

\section{References}

1. Kensler TW, Qian GS, Chen JG and Groopman JD: Translational strategies for cancer prevention in liver. Nat Rev Cancer 3: 321-329, 2003.

2. Forner A, Llovet JM and Bruix J: Hepatocellular carcinoma. Lancet 379: 1245-1255, 2012.

3. Tung-Ping Poon R, Fan ST and Wong J: Risk factors, prevention, and management of postoperative recurrence after resection of hepatocellular carcinoma. Ann Surg 232: 10-24, 2000.

4. Thiery JP: Epithelial-mesenchymal transitions in tumour progression. Nat Rev Cancer 2: 442-454, 2002.

5. Grünert S, Jechlinger $M$ and Beug $\mathrm{H}$ : Diverse cellular and molecular mechanisms contribute to epithelial plasticity and metastasis. Nat Rev Mol Cell Biol 4: 657-665, 2003.

6. Lee TK, Man K, Poon RT, Lo CM, Yuen AP, Ng IO, Ng KT, Leonard W and Fan ST: Signal transducers and activators of transcription $5 \mathrm{~b}$ activation enhances hepatocellular carcinoma aggressiveness through induction of epithelial-mesenchymal transition. Cancer Res 66: 9948-9956, 2006.

7. Huang C, Cao J, Huang KJ, Zhang F, Jiang T, Zhu L and Qiu ZJ: Inhibition of STAT3 activity with AG490 decreases the invasion of human pancreatic cancer cells in vitro. Cancer Sci 97: $1417-1423,2006$.

8. Kusaba T, Nakayama T, Yamazumi K, Yakata Y, Yoshizaki A, Nagayasu T and Sekine I: Expression of p-STAT3 in human colorectal adenocarcinoma and adenoma; correlation with clinicopathological factors. J Clin Pathol 58: 833-838, 2005.

9. Suiqing C, Min Z and Lirong C: Overexpression of phosphorylated-STAT3 correlated with the invasion and metastasis of cutaneous squamous cell carcinoma. J Dermatol 32: 354-360, 2005.

10. Huang C, Yang G, Jiang T, Zhu G, Li H and Qiu Z: The effects and mechanisms of blockage of STAT3 signaling pathway on IL-6 inducing EMT in human pancreatic cancer cells in vitro. Neoplasma 58: 396-405, 2011.

11. Lo HW, Hsu SC, Xia W, Cao X, Shih JY, Wei Y, Abbruzzese JL, Hortobagyi GN and Hung MC: Epidermal growth factor receptor cooperates with signal transducer and activator of transcription 3 to induce epithelial-mesenchymal transition in cancer cells via up-regulation of TWIST gene expression. Cancer Res 67: 9066-9076, 2007.

12. Cheng GZ, Zhang WZ, Sun M, Wang Q, Coppola D, Mansour M, $\mathrm{Xu}$ LM, Costanzo C, Cheng JQ and Wang LH: Twist is transcriptionally induced by activation of STAT3 and mediates STAT3 oncogenic function. J Biol Chem 283: 14665-14673, 2008.

13. Xiong $\mathrm{H}$, Hong J, Du W, et al: Roles of STAT3 and ZEB1 proteins in E-cadherin down-regulation and human colorectal cancer epithelial-mesenchymal transition. J Biol Chem 287: 5819-5832, 2012.

14. Zhang CH, Xu GL, Jia WD, Li JS, Ma JL, Ren WH, Ge YS, Yu JH, Liu WB and Wang W: Activation of STAT3 signal pathway correlates with twist and E-cadherin expression in hepatocellular carcinoma and their clinical significance. J Surg Res 174: 120-129, 2012.

15. Zhang W, Zhu XD, Sun HC, Xiong YQ, Zhuang PY, Xu HX, Kong LQ, Wang L, Wu WZ and Tang ZY: Depletion of tumorassociated macrophages enhances the effect of sorafenib in metastatic liver cancer models by antimetastatic and antiangiogenic effects. Clin Cancer Res 16: 3420-3430, 2010.
16. Li Y, Tian B, Yang J, Zhao L, Wu X, Ye SL, Liu YK and Tang ZY: Stepwise metastatic human hepatocellular carcinoma cell model system with multiple metastatic potentials established through consecutive in vivo selection and studies on metastatic characteristics. J Cancer Res Clin Oncol 130: 460-468, 2004.

17. Levy DE and Darnell JE Jr: Stats: Transcriptional control and biological impact. Nat Rev Mol Cell Biol 3: 651-662, 2002.

18. Xu Q, Briggs J, Park S, et al: Targeting Stat3 blocks both HIF-1 and VEGF expression induced by multiple oncogenic growth signaling pathways. Oncogene 24: 5552-5560, 2005.

19. Yang J, Mani SA, Donaher JL, Ramaswamy S, Itzykson RA, Come C, Savagner P, Gitelman I, Richardson A and Weinberg RA: Twist, a master regulator of morphogenesis, plays an essential role in tumor metastasis. Cell 117: 927-939, 2004.

20. Chen L, Chan TH, Yuan YF, et al: CHD1L promotes hepatocellular carcinoma progression and metastasis in mice and is associated with these processes in human patients. J Clin Invest 120: 1178-1191, 2010

21. Tang DJ, Dong SS, Ma NF, Xie D, Chen L, Fu L, Lau SH, Li Y, $\mathrm{Li} \mathrm{Y}$ and Guan XY: Overexpression of eukaryotic initiation factor 5A2 enhances cell motility and promotes tumor metastasis in hepatocellular carcinoma. Hepatology 51: 1255-1263, 2010.

22. Cho KH, Jeong KJ, Shin SC, Kang J, Park CG and Lee HY: STAT3 mediates TGF- $\beta 1$-induced TWIST1 expression and prostate cancer invasion. Cancer Lett 336: 167-173, 2013.

23. Taylor KM, Hiscox S and Nicholson RI: Zinc transporter LIV-1: a link between cellular development and cancer progression. Trends Endocrinol Metab 15: 461-463, 2004.

24. Frixen UH, Behrens J, Sachs M, Eberle G, Voss B, Warda A, Löchner D and Birchmeier W: E-cadherin-mediated cell-cell adhesion prevents invasiveness of human carcinoma cells. J Cell Biol 113: 173-185, 1991.

25. Birchmeier $\mathrm{W}$ and Behrens $\mathrm{J}$ : Cadherin expression in carcinomas: role in the formation of cell junctions and the prevention of invasiveness. Biochim Biophys Acta 1198: 11-26, 1994.

26. Troyanovsky S: Cadherin dimers in cell-cell adhesion. Eur J Cell Biol 84: 225-233, 2005.

27. Bukholm IK, Nesland JM, Kåresen R, Jacobsen U and BørresenDale AL: E-cadherin and $\alpha-, \beta-$, and $\gamma$-catenin protein expression in relation to metastasis in human breast carcinoma. J Pathol 185: 262-266, 1998.

28. Tomita K, van Bokhoven A, van Leenders GJ, Ruijter ET, Jansen CF, Bussemakers MJ and Schalken JA: Cadherin switching in human prostate cancer progression. Cancer Res 60: 3650-3654, 2000.

29. Islam S, Carey TE, Wolf GT, Wheelock MJ and Johnson KR: Expression of $\mathrm{N}$-cadherin by human squamous carcinoma cells induces a scattered fibroblastic phenotype with disrupted cell-cell adhesion. J Cell Biol 135: 1643-1654, 1996.

30. Iwatsuki H, Sasaki K, Suda M and Itano C: Vimentin intermediate filament protein as differentiation marker of optic vesicle epithelium in the chick embryo. Acta Histochem 101: 369-382, 1999.

31. Hu L, Lau SH, Tzang CH, et al: Association of Vimentin overexpression and hepatocellular carcinoma metastasis. Oncogene 23: 298-302, 2004

32. Grimstad IA: Direct evidence that cancer cell locomotion contributes importantly to invasion. Exp Cell Res 173: 515-523, 1987.

33. Peinado H, Portillo F and Cano A: Transcriptional regulation of cadherins during development and carcinogenesis. Int J Dev Biol 48: 365-375, 2004.

34. Tania M, Khan MA and Fu J: Epithelial to mesenchymal transition inducing transcription factors and metastatic cancer. Tumour Biol 35: 7335-7342, 2014

35. Lee TK, Poon RT, Yuen AP, et al: Twist overexpression correlates with hepatocellular carcinoma metastasis through induction of epithelial-mesenchymal transition. Clin Cancer Res 12: 5369-5376, 2006

36. Kang Y and Massagué J: Epithelial-mesenchymal transitions: Twist in development and metastasis. Cell 118: 277-279, 2004. 